\title{
GreENiNg ACTIVITIES IN WAREHOUSES: A MODEL FOR IDENTIFYING SUSTAINABLE STRATEGIES IN MATERIAL HANDLING
}

\author{
Francesco Boenzi, Salvatore Digiesi, Francesco Facchini, \\ Giorgio Mossa, Giovanni Mummolo
}

Department of Mechanics, Matematics and Management - Politecnico di Bari, V.le Japigia 182, Bari 70126, Italy

\begin{abstract}
Recently many firms adopted a "green warehousing” approach in order to improve their environmental performances. The common driver of the solutions identified is in the reduction of the energy consumptions, considered as the key "greening element". The optimization of energy required by order picking (estimated to count up to 55\% of the total energy for warehousing activities) can be obtained by means of the adoption of forklift equipped by different engines or by means of the optimization of operational activities such as the pickers routing, the movements for material handling, etc. In literature, the type of forklift and the storage configuration to be adopted are addressed as different issues. In this study a support decision tool based on an iterative nonlinear integer model is developed. The tool allows identifying the strategy (the type of forklift and the storage configuration to be adopted) optimizing the environmental performances of warehouse activities.
\end{abstract}

Keywords: Sustainable logistic, Order picking, Green warehousing, Material handling, Warehouse management
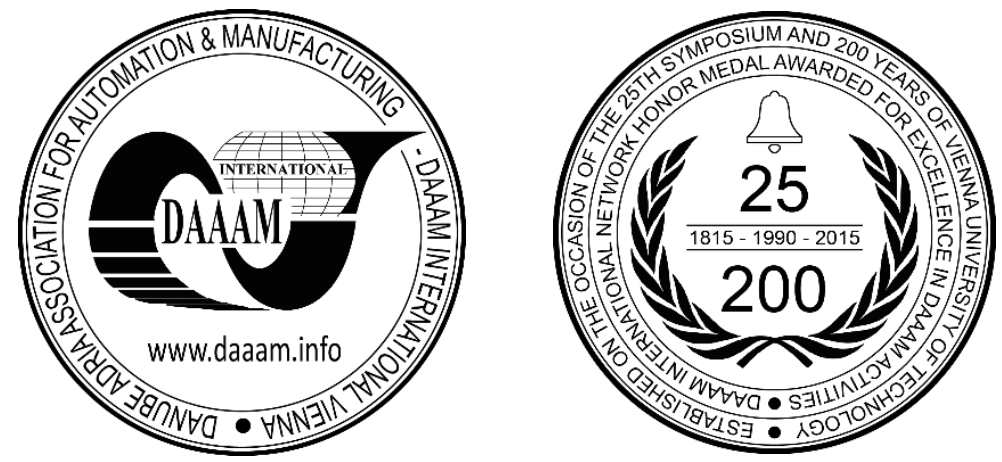

This Publication has to be referred as: Boenzi, F[rancesco]; Digiesi, S[alvatore]; Facchini, F[rancesco]; Mossa, G[iorgio] \& Mummolo, G[iovanni] (2016). Greening Activities in Warehouses: A Model for Identifying Sustainable Strategies in Material Handling, Proceedings of the 26th DAAAM International Symposium, pp.0980-0988, B. Katalinic (Ed.), Published by DAAAM International, ISBN 978-3-902734-07-5, ISSN 1726-9679, Vienna, Austria DOI: $10.2507 / 26$ th.daaam.proceedings. 138 


\section{Introduction}

Environmentally sustainable (green) supply chain management (GSCM) is a concept that is gaining importance all over the world. It represents an important organizational philosophy to achieve profit and market share objectives by reducing environmental impacts and ensuring an ecological efficiency of organizations and their partners. Companies implement the greening process into their businesses for three main reasons: they have to comply with environmental regulations (legislation), to address environmental concerns of their customers (marketing), and to mitigate the environmental impact of their production activities (ecological awareness). According to the Council of Supply Chain Professionals (CSCP): "Supply Chain Management (SCM) encompasses the planning and management of all activities involved in sourcing and procurement, conversion, and all logistics management activities. Importantly, it also includes coordination and collaboration with channel partners, which can be suppliers, intermediaries, third party service providers, and customers. In essence, supply chain management integrates supply and demand management within and across companies". Currently, an increasing request for more sustainable solutions of logistic issues able to minimize the external costs due to both inbound logistic (material handling, forklift routing, pick orders, etc.) and outbound logistic (packing, shipments, transportation, etc.) has been observed [1,2]. External costs due to logistic management activities include the costs of accidents, emissions and noise as well as operation and maintenance of infrastructures.

Focusing on the three basic groups of activities mentioned in the definition of SCM (see fig. 1), the green warehousing is a new approach adopted in order to optimize the environmental performances of the inbound logistic activities. Many strategies could be evaluated for increasing the sustainability of the main warehousing activities: each strategy reducing the energy consumption or the material usage/waste can be considered as a "green element". The overall energy consumption and efficiency of a warehouse depends on the different in-house processes. In most cases, about 70 $80 \%$ of the overall energy required for the warehousing activities depends on the degree of automation, electricity, oil and gas consumption for material handling activities. The remaining 20 to $30 \%$ is indirect energy related to the daily commuting of the employees between their homes and work [3]

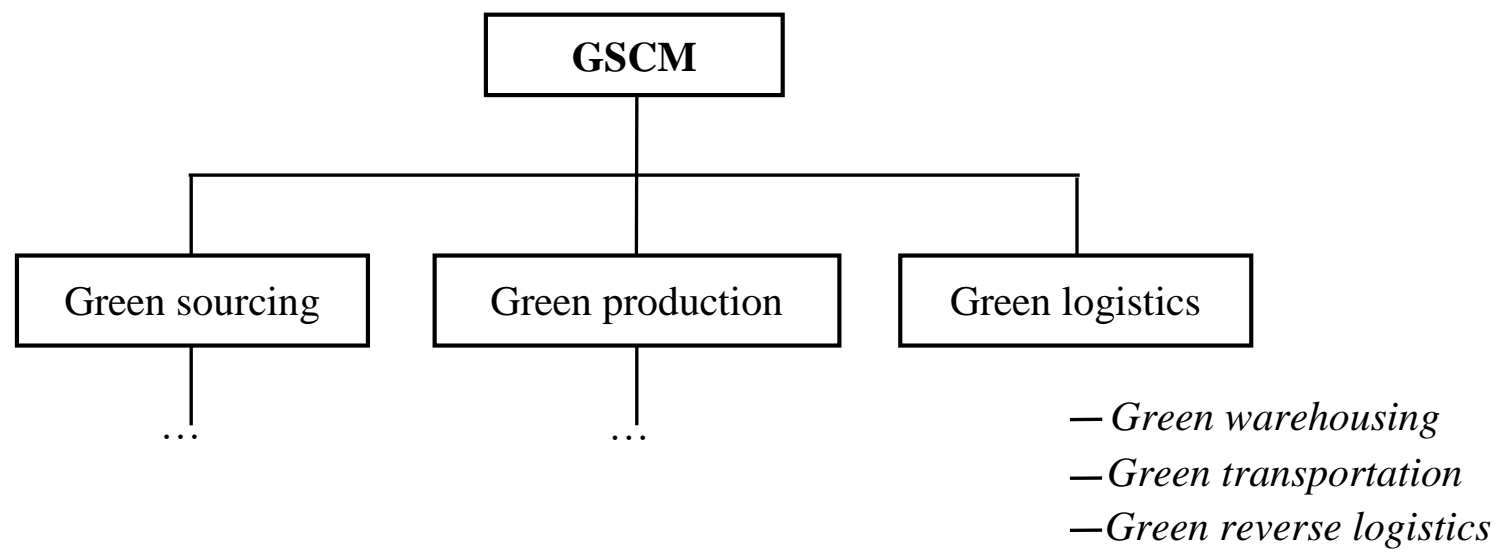

Fig. 1. (a) Segments of Green Supply Chain Management.

The optimization of energy consumption can be obtained by means of the adoption, in the same warehouse, of forklift equipped by different engines (LPG, diesel, electric). Indeed, recently on the market new forklifts characterized by low emission and energy consumption are available. New technologies for liquid propane forklift that allow them to burn cleaner and be more fuel-efficient are available. Electric hybrid forklifts and non-road vehicle powered by hydrogen fuel cells are also great examples of new forklift technologies that could be used in order to minimize the environmental impact and provide better energy efficiency and/or operational performances. The most popular forklifts engines still remain the diesel and the LPG ones, representing about half of the world total forklift fleet. The sales of LPG forklifts in US represented about 1/3 of the large forklift sales in 2005 (source: The British Industrial Truck Association). In Europe, the predominant technology is the battery- powered forklift. In the global market, the three types of forklifts have the same weight (see figure 2).

The choice of one forklift characterized by low energy consumption is not the only strategy to minimize the environmental impact of the warehousing activities. It is possible to ensure a low level of emission and minimal energy consumption by adopting a material handling strategy able to reduce the times and the costs of inbound logistic activities. It is well known that order-picking process, defined as the process of retrieving items from storage locations in response to a specific customer request, is the most laborious and the most costly activity in a typical warehouse, with up to $55 \%$ of warehouse total operating costs [4].

Different types of order picking system are adopted in warehouses; among them, one of the most common system in industrial settings is the picker-to-part order picking system where items are stored on racks or bins such that a picker travelling in a direction (walking or driving along the aisles) is able to retrieves or stocks all the items specified in a picking list. Therefore in such a system, the dominant component of the picking time is the travel time [5]. 

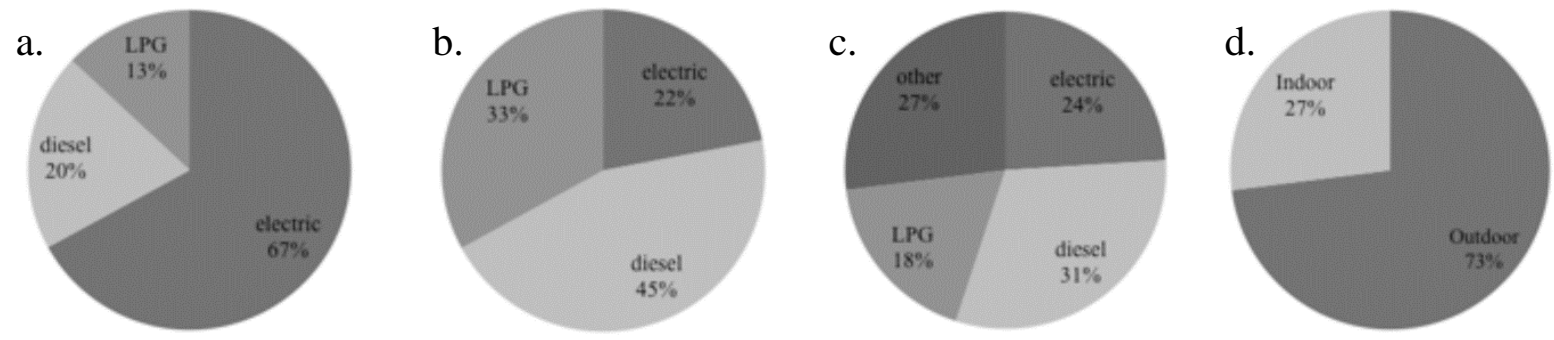

Fig. 2. a. forklifts distribution in EU market; b. forklifts distribution in US market; c. forklifts distribution in the worldwide market; $d$. forklifts distribution for typologies of work environment

It is shown that the interaction between the routing method and the storage assignment is important in a manual order picking system. Indeed, a storage assignment rule provides an effective way of locating products in order to improve the operational efficiency of order picking [6]. In scientific literature many heuristic methods for storage assignment have been proposed. Class-based storage policies classify items into classes and usually assign a fixed area to each class in which items are randomly allocated in that area. Recently an optimal solution procedure for storage class formation by considering area usage, handling cost and storage space cost has been developed [7]. Chan and Chan presented a simulation study of a real case concerning storage assignment issue in a manual-pick with multi-level-rack warehouse, and demonstrated that the key element for an effective implementation of a storage assignment system is to match the types of warehouse storage systems and the variety of items in the customer orders [8].

As far as concern the routing policies, the goal is to obtain a sequence of items to be retrieved from racks such as the total travel distance is as short as possible. For picker-to-part order picking systems, numerous routing methods, including optimization algorithms, have been proposed. The performance of these heuristics depends on the particular operating conditions of the system observed. The adoption of heuristic methods, allow a reduction between $17 \%$ and $34 \%$ in the path length of the forklift within a warehouse [9]. The return, traversal and midpoint policies are prevalent routing strategies: in the first policy, a picker enters the aisles containing picks from one end to perform the pick, and then exits from the same end (see fig. 3a). The simplest routing policy is the traversal one, also called $S$-shape policy, where a picker enters an aisle containing items in the order from one end and leaves from the opposite end under traversal policy (see fig. 3b). In the midpoint policy the warehouse is equally divided into two areas where a picker accesses the front half of an aisle from the front cross aisle, and the back half from the back cross aisle (see fig. 3c). Three analytical models have been proposed in order to evaluate the expected travel distance for these three routing policies and examined their performance by varying the parameter values of the COI-based (Cube-per-Order Index) ABC curve, number of items in the list, and ratio of the length to the width of the warehouse [10]. Goetschalckx and McGinnis indicated that an analytical model is important for both warehouse design and operation purposes [11].

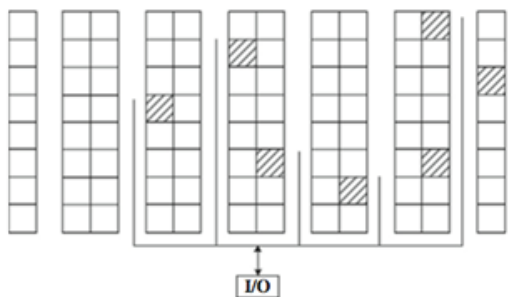

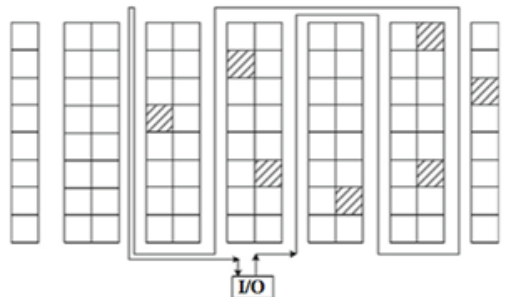

b

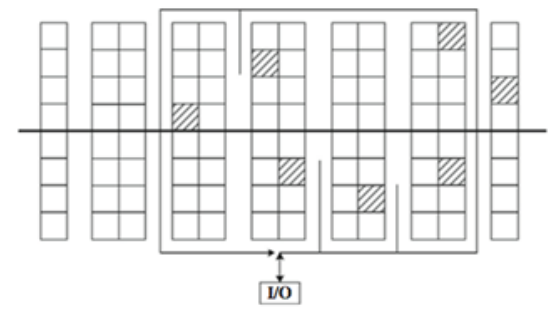

C

Fig. 3. Routing policies (a) Return, (b) Traversal and Midpoint (c)

The order-picking methods and the technologies above described allow to reduce the estimated travel time and/or increase the productivity of the warehouse activities, but in many cases this is a necessary but not sufficient condition for implementing a 'greening process' into the warehouse and ensure the minimization of the environmental impact. The target of the above-mentioned models is not the improving of the environmental performances of the system (e.g. carbon footprint, $\mathrm{CO}_{2}$ emission, external costs, etc.) but the reduction of travel distance and/or order retrieval time. Moreover, they neglect the performance of the non-road vehicle adopted for material handling activities. In the attempt of minimize the environmental impacts, these aspects become crucial, since the best logistic strategy for a sustainable warehousing has to be identified by means of the joint evaluation of all aspects related to material handling activities, including the type of the forklift to be adopted (LPG, Diesel or Electric).

The aim of this study is to develop a support decision tool that, through an iterative non-linear integer model, is able to suggest the suitable strategy in order to optimize the environmental performance of the internal logistic activities in the warehouse. The strategy suggested by the tool is obtained by means of the evaluation of different storage configurations on the basis of the type of the forklift adopted (internal combustion or electric engine equipped) for performing order picking activities. 
Notations adopted in the model are listed below:
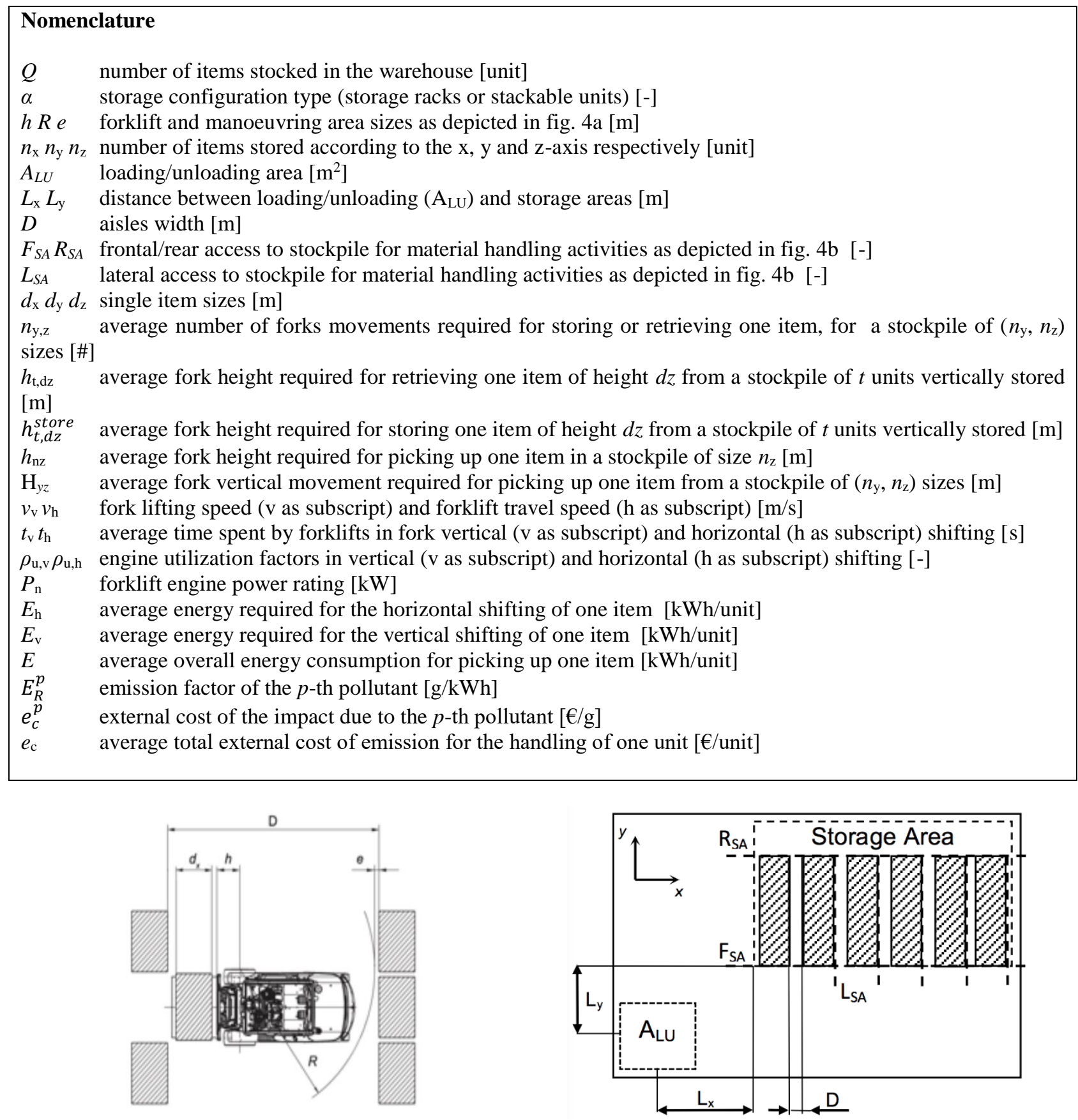

Fig. 4. A.technical features of the forklift related to manoeuvring area sizes; b. layout of the warehouse considered in the model

The remaining of the paper is organized as follows: in section 2, the model is presented and input and output parameters are detailed; in section 3, the model is applied to different test cases and the results obtained are presented and discussed; conclusions are in section 4.

\section{The Model}

\subsection{General assumptions}

The support decision tool developed is based on a non-linear integer programming model allowing evaluating the overall emission due to forklift operation in each phase of the material handling cycle: transport, picking and retrieving of the stored items. The order - picking strategy considered for the warehouse management is based on a low level pickerto-parts system employing workers and forklifts. 
The model is defined under the following assumptions:

1. each item is independent of the other items within an order;

2. all the information about the orders to be picked in are known in advance;

3. the total number of items stocked in the warehouse is constant and all items stocked in the warehouse have prismatic form and are characterized by the same sizes (dx, dy, and dz) and weight;

4. the items are stocked in stockpiles of the same height;

5. a storage configuration is univocally identified by two integer numbers (ny, nz), being $n x=Q /(n y \cdot n z)$;

6. the storage configuration adopted in the warehouse can be only of two types: stackable units or with storage racks;

7. the material handling in the warehouse is operated by means of counterbalance forklifts carrying on one item for each load/unload cycle;

8. the effects of the acceleration and deceleration of the forklift can be neglected;

9. warehouse layout considered is as depicted in fig. 4b;

10. the distance between loading/unloading area of the warehouse and the stockpiles area $\left(\mathrm{L}_{\mathrm{x}}, \mathrm{L}_{\mathrm{y}}\right)$ is constant;

11. the distance between stockpiles (aisles) according to the X-axis, is equal to zero in case of storage with stackable units (see fig. 4b), while in case of rack storage the width of the aisles is constant and equal to parameter D related to maneuvering area of the forklift;

12. each stockpile can be accessed by both sides ( $\mathrm{F}_{\mathrm{SA}}$ and $\mathrm{R}_{\mathrm{SA}}$ in fig. $\left.4 \mathrm{~b}\right)$ for storage configuration characterized by stackable units, while adopting a rack as storage configuration, the stockpile can be accessed only by lateral side ( $\mathrm{L}_{\mathrm{SA}}$ in fig. $4 \mathrm{~b}$ );

13. capacity and dimensional constraints for the warehouse are not considered.

The material handling process considered in the model consists of three main steps:

1. unloaded forklift starts from loading/unloading area $\left(A_{L U}\right)$ of the warehouse and drives to the storage area; a constant speed of $15.0[\mathrm{~km} / \mathrm{h}]$ is assumed in this phase;

2. forklift stops in the storage area and picks the load; it is assumed that the energy and the time spent for the retrieving of the load depend on: weight of the load, lift speed of the forks, average number of forks movements, and average fork height required for the retrieving of one item;

Loaded forklift starts from storage area and drives to the loading/unloading area (ALU) of the warehouse; the carrying speed depends on the weight of the load; for heavy loads $(3000 \div 4000$ [kg]) the average speed assumed is 5.0 [km/h], while for light loads $(500 \div 1000[\mathrm{~kg}])$ a carrying speed value of $12.0[\mathrm{~km} / \mathrm{h}]$ is assumed.

\subsection{Theoretical formulation}

The proposed model allows to jointly identify the storage configuration and the type of forklift to be adopted minimizing the average overall energy required for the material handling activities in a warehouse. A storage configuration is identified by means of the numbers of items to be stored according to $\mathrm{x}, \mathrm{y}$, and $\mathrm{z}$ directions of the stockpile $\left(n_{\mathrm{x}}, n_{\mathrm{y}}\right.$, and $\left.n_{\mathrm{z}}\right)$.

The input parameters of the model are listed below:

i. the technical specifications of available forklifts:

a. lifting speed $\left(v_{v}\right)$ and travel speed $\left(v_{h}\right)$,

b. engine utilization factors in vertical and horizontal shifting $\left(\rho_{u, v} \rho_{u, h}\right)$,

c. engine power rating $\left(P_{n}\right)$,

d. engine emission factors $\left(E_{R}^{p}\right)$;

ii. size $\left(d_{\mathrm{x}} d_{\mathrm{y}} d_{\mathrm{z}}\right)$, and weight of the single items to be stocked;

iii. storage configuration type (stackable units or with storage racks);

The objective function of the model is expressed in equation (1), where $E$ is the average overall energy required by the forklift for the material handling activities.

$$
\min _{n_{x}, n_{y}, n_{z}} E
$$

The energy (E), minimized in equation (1), depends by parameters $E_{\mathrm{v}}$ and $E_{\mathrm{h}}$ that identify the average energies required by the forklift for the lifting/lower and transfer activities (2).

$$
E=E_{v}+E_{h}
$$

In equations (3) and (4), $P_{\mathrm{n}}$ is the nominal power of the engine that equips the forklift, $\rho_{\mathrm{u}, \mathrm{v}}$ and $\rho_{\mathrm{u}, \mathrm{h}}$ are the engine utilization factors for vertical shifting (lifting/lower activities) and horizontal shifting (transfer activity) of the forklift; $t_{\mathrm{v}}$ and $t_{\mathrm{h}}$ are the average time for the vertical and horizontal shifting, respectively. 


$$
\begin{aligned}
& E_{v}=P_{n} \rho_{u, v} t_{v} \\
& E_{h}=P_{n} \rho_{u, h} t_{h}
\end{aligned}
$$

Parameters $t_{v}$ and $t_{h}$ depend on the distance and the speed of the shifting; $t_{h}$ parameter depends on the distances $L_{h}$ identified by equation (5) and by the transfer speed of the forklift; $t_{\mathrm{v}}$ parameter depends on the average vertical distance $\left(\mathrm{H}_{\mathrm{y}, \mathrm{z}}\right)$ due to lifting phase for the storage and retrieval of the items; the average forks vertical movements values are evaluated by means of equation (6).

$$
\left.L_{h}=2\left\{L_{x}+\left(n_{x}-1\right) d_{x}+\alpha\left[d_{x}+\left(n_{x}-1\right) D+D / 2\right]\right\}+L_{y}+\left(n_{y}-1\right) d_{y}+d_{y} / 2\right\}
$$

$\alpha=1$ if the items are stored in racks; $\alpha=0$ if the items are stored without racks;

$$
H_{y, z}=n_{y, z} h_{n_{z}}
$$

In equation (6), $n_{y, z}$ is the average number of the material handling movements required for storing or retrieving one item by the stockpile. In case of items are stored in racks, $n_{\mathrm{y}, \mathrm{z}}$ is equal to 1 ; in case there are no racks, $n_{\mathrm{y}, \mathrm{z}}$ is obtained by equations $(7-8)$. As far as concern $h_{\mathrm{nz}}$, it allows evaluating the average forks height required for picking up one item from a stockpile respectively adopting a storage configuration with rack (9) or with stackable units (10).

$$
\begin{aligned}
& n_{y, z}=\frac{\left(n_{z}+1\right)\left(n_{y}+2\right)}{8} \\
& n_{y, z}=\frac{\left(n_{z}+1\right)}{2 n_{y}}\left[\frac{\left(n_{y}{ }^{2}-1\right)}{4}+\frac{\left(n_{y}-1\right)}{2}+1\right] \\
& h_{n_{z}}=\left(n_{z}-1\right) d_{z} \\
& h_{n_{z}}=\frac{1}{n_{z}} \sum_{t=1}^{n_{z}} h_{t, d_{z}}+h_{t, d_{z}}^{\text {store }}
\end{aligned}
$$

The first term in equations (10) measures the average forks height required for retrieving one item from a stockpile of type $\left(n_{\mathrm{x}}, n_{\mathrm{y}}, n_{\mathrm{z}}\right)$, and the second term the corresponding value for storing one item in the same stockpile. Parameter $h_{\mathrm{td} z}$ measures the overall forks vertical movements required for retrieving one item with dimension $d_{z}$ from a stockpile of type $\left(n_{\mathrm{x}}, n_{\mathrm{y}}=1, t\right)$, and must be computed for all the values of $t$ ranging in $\left(1 ; n_{\mathrm{z}}\right)$ by means of equation (11). Average forks height required for storing one items in a stockpile of type $\left(n_{\mathrm{x}}, n_{\mathrm{y}}=1, t\right)$ is computed by means of equation (12).

$$
\begin{aligned}
& h_{t, d_{z}}=\frac{1}{t} \sum_{k=1}^{t}\left[(t-1)^{2}-\left(k^{2}-3 k+2\right)\right] d_{z} \\
& h_{t, d_{z}}^{\text {store }}=\frac{1}{t} \sum_{k=1}^{t}(k-1) d_{z}
\end{aligned}
$$

\subsection{Environmental impact assessment}

Starting from the solution of problem (1), an environmental impact assessment is required in order to identify the strategy characterized by the best environmental performance. In this phase, the type of forklift to be adopted is identified. Forklifts commercially available are powered with three different types of engine: diesel, electrical and Liquefied Petroleum Gas (LPG) engine. Each of them is characterized by different value of the nominal capacity, tailpipe emissions, management costs, etc. Starting from the average amount of energy required for picking up one item from a stockpile, the related average external costs are evaluated by means of equations (13) and (14) in case of Diesel/LPG engine equipped forklifts and electrical powered forklifts, respectively.

$$
\begin{aligned}
& e_{C}^{\text {Diesel } / L P G}=E\left(E_{R}^{N O_{x}} e_{C}^{N O_{x}}+E_{R}^{C O} e_{C}^{C O}\right) \\
& e_{C}^{\text {Electric }}=E e_{C}^{\text {electricity }}
\end{aligned}
$$

In both cases, the external costs are evaluated as the product of the average amount of energy required for picking up one item and the unitary external cost $[€ / \mathrm{kWh}]$. In case of Diesel/LPG engine equipped forklifts, the unitary external cost is obtained as the sum of the products of the pollutants emission rates and the related unitary monetary costs (see eq. 12). 
Generation rate values and monetary costs of emissions assumed in this work are shown in table 1 and are from [12]. In case of electrical powered forklifts (see eq. 13), the unit external cost assumed is referred to the Italian mix of power generation, corresponding to $0.05[€ / \mathrm{kWh}]$.

\begin{tabular}{lll}
\hline \multirow{2}{*}{ Pollutant $(p)$} & \multicolumn{2}{c}{ Emission Rate $\left(\boldsymbol{E}_{\boldsymbol{R}}^{\boldsymbol{p}}\right)[\mathrm{g} / \mathrm{kwh}]$} \\
\cline { 2 - 3 } & Diesel & LPG \\
\hline NOx & 10.8 & 15.6 \\
CO & 45.0 & 10.9 \\
\hline
\end{tabular}

Table 1. Diesel and LPG engine emission

Starting from the solution of (1), the type of forklift to be adopted is identified as the one ensuring the best environmental performances, measured in terms of external costs by means of (13) or (14).

\section{Test cases}

The model has been applied to different test cases, in which three counter- balance forklifts have been considered. They are produced by OM- Still ${ }^{\circledR}$ and are identified with the model numbers: RX70-40, RX70-40T, RX6040/600; they are equipped with a Diesel, a LPG and an electric engine, respectively. As far as concern the overall number of items to be stored $(Q)$ five different quantities have been considered; in all cases considered, all items are characterized by the same sizes and weights (see tab. 2). The warehouse layout assumed is shown in fig. 5 , where the distance $\left(L_{\mathrm{x}}, L_{\mathrm{y}}\right)$ between $A_{\mathrm{LU}}$ and storage area is equal to 10 [m] (for both sides), the width of the aisles (only for storage configuration with racks) is related to $h, R$ and $e$ parameters that depend on maneuvering area of the forklift (fig. 4). As far as concern the storage configuration of the items, in the test cases both stackable units and storage racks have been considered.

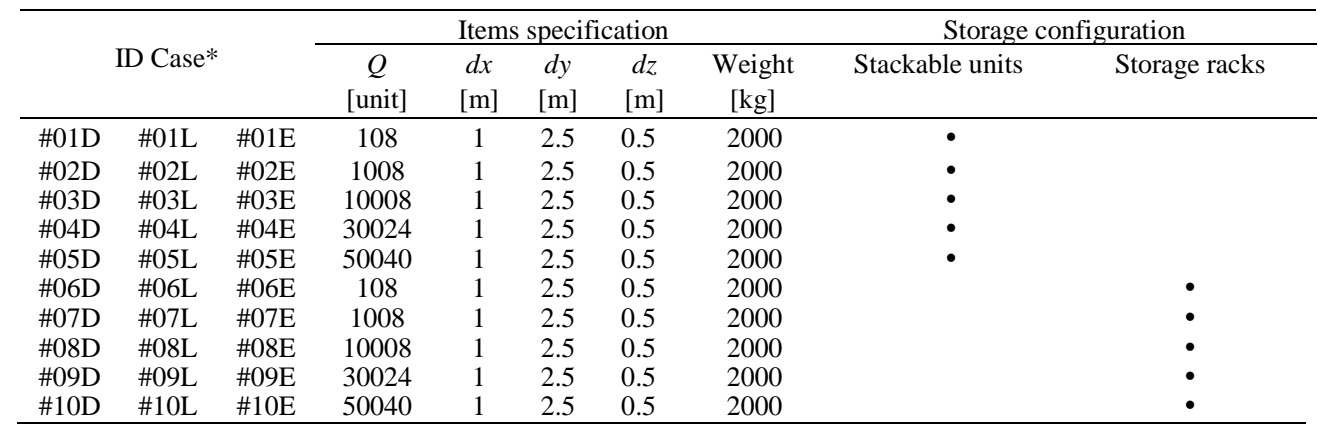

Table 2. List of input parameters for each test case

The model has been applied in each test case in order to to identify the suitable strategy allowing to minimize the overall external costs. Model results for some test cases are listed in table 3 . The adoption of forklifts equipped by different engines leads the model to identify different solutions for the order picking strategies. In particular, in case no racks are adopted, high value of $n_{\mathrm{z}}$ and low values of $n_{\mathrm{x}}$ and/or $n_{\mathrm{y}}$ ensure a green warehousing activities in case forklift equipped by internal combustion engine (output parameters very similar to diesel engine, are obtained for LGP forklift) are adopted. is identified for This means that, in these conditions, the emissions due to lift-up of the items, are lower if compared to the emissions due to horizontal shifting. On the contrary, in case of electrical forklift, the more sustainable strategy is characterized by a higher number of horizontal shifts rather that forks movements.

As far as concern the storage configuration in case of racks, the decision variable values that minimize the external cost are very similar independently by the forklifts adopted. In these cases the optimal storage configurations, suggested by the support decision tool, are characterized by low values of $n_{\mathrm{x}}$ and high values of $n_{\mathrm{y}}$ and $n_{\mathrm{z}}$. The low number of the items stocked according to $\mathrm{x}$-axes is due to the presence of aisles between stockpiles $(D \neq 0)$; on the contrary the increase of the items stored according $\mathrm{z}$-axes depends on the low average number of the forks movements required for storing or retrieving one item. Indeed, adopting storage racks in warehouse, the picking of the single item do not required the repositioning of other items, so $n_{\mathrm{y}, \mathrm{z}}$ is equal to 1 for the handling of all items.

\begin{tabular}{ccccccccccc}
\hline $\begin{array}{c}\text { Decision } \\
\text { variable } \\
{[\text { unit] }}\end{array}$ & $\# 01 \mathrm{D}$ & $\# 01 \mathrm{E}$ & $\# 02 \mathrm{D}$ & $\# 02 \mathrm{E}$ & $\# 03 \mathrm{D}$ & $\# 03 \mathrm{E}$ & $\# 06 \mathrm{D}$ & $\# 06 \mathrm{E}$ & $\# 08 \mathrm{D}$ & $\# 08 \mathrm{E}$ \\
\hline$n x$ & 12 & 18 & 42 & 42 & 139 & 139 & 3 & 3 & 12 & 12 \\
$n y$ & 3 & 3 & 8 & 12 & 24 & 36 & 6 & 6 & 139 & 139 \\
$n z$ & 3 & 2 & 3 & 2 & 3 & 2 & 6 & 6 & 6 & 6 \\
\hline
\end{tabular}

Table 3. Model results for some test cases considered 
There is a strong link between decision variables values identified for storing the items and the corresponding external costs. It has been observed that varying $n_{\mathrm{x}}, n_{\mathrm{y}}$, and $n_{\mathrm{z}}$ parameters, the average external costs change significantly (up to ten times more). Moreover, in many cases the average external costs of the logistic strategies identified as optimal by the model in case of the adoption of electric forklifts for the material handling activities are higher if compared to that obtained in case of LPG/Diesel engine forklifts adoption. This leads to conclude that for the same number of items $(Q)$ to be stored, the use of electric forklift does not always ensure the minimal environmental impact of the material handling activities in a warehouse.
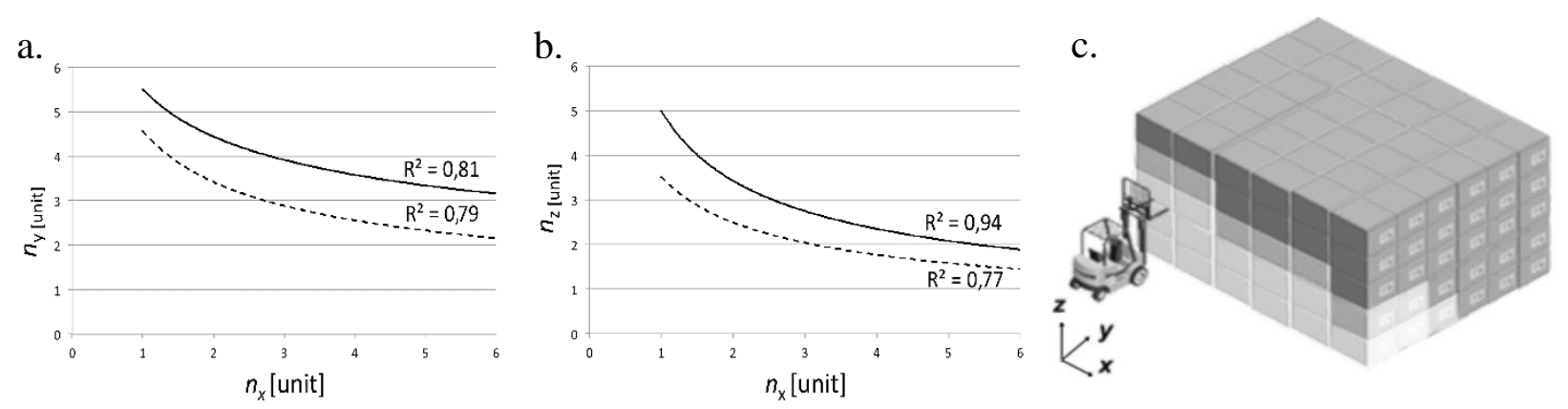

Fig. 5. Isoenergetic curves using a diesel forklift adopting stackable units

In order to identify the sustainable warehousing strategies, varying the quantities of the items to be stored, the model has been applied in order to to obtain the isoenergetic curves shown in figures $6 \mathrm{a}$ and $6 \mathrm{~b}$.As it can be observed, the energy required for picking/retrieving the single item is strongly related to its position in the stockpile (identified by $n_{\mathrm{x}}$, $n_{\mathrm{y}}$, and $n_{\mathrm{z}}$ parameters) and to the storage configuration adopted in the warehouse (storage racks or stackable units). The curves in fig. 6 have been obtained in case of $Q=180$ and the adoption of diesel forklift and stackable units as configuration storage. As depicted in figure $6 \mathrm{c}$, it is possible noted that the energy required for handling items in case no racks are adopted, strongly depends on their position on the stack. In fig. 6c items with light-grey colour are characterized by low level of energy, while with grey and dark grey colours are identified items that required higher energy level to be handled. As far as concern the amount of the energy required in case of LPG or electric engine forklift, the corresponding isoenergetic curves are characterized by the same trends, but significant differences in the energy values are observed.

\section{Conclusion}

Warehouses still play a key role in supply chains, since they allow mitigating variations in supply and demand, and provide value-added services [13]. A correct management of warehouse storage and picking actions can significantly impact the success of logistics operations in most manufacturing companies and play a vital role in their survival [14]. In order to increase the productivity of the warehouse activities, most scientific studies are focused on the identification of the different order-picking strategies that allow to reduce the travel time estimation, optimize the storage assignment, minimize the path of the forklift within the warehouse, and identify further policies addressed to the minimization of the warehouse management costs. But in many cases, the adoption of these models cannot be enough to ensure the minimization of the environmental impact.

In a green warehouse, indeed, the energy consumption due to material handling activities is considered as the key "greening element"; for this reason, the type of the engine that equips the forklift adopted, the number of the elementary movements required for the material handling, and other aspects related to energy required by warehousing activities, cannot be neglected. Therefore in order to minimize the environmental impact, the best logistic strategy has to be identified as a joint evaluation of all energetic aspects related to both to material handling activities and by the features of the forklift adopted (LPG, Diesel or Electric).

The support decision tool described in this paper allows to evaluate the overall impact due to all energyconsumptive factors of the warehousing activities and drives the user in identifying the best logistic solutions in order to minimize the environmental impact of the material handling activities. The application of the model to different test cases shows the capabilities in identifying optimal logistic strategies that ensuring a low environment impact due to inbound logistic activities. Results show how it is possible to identify different strategies that allow to obtain a significant reduction of external costs for a given number of stored items (all characterized by the same sizes and weight), by adopting different storage configurations and typologies of forklifts.

The main limits of the model proposed are in the single-type of item to be stored considered, since often this is not the case in an industrial warehouse. Moreover, the model has to be further developed in order to include more optimization criteria in its objective function (inventory turnover index, time of loading and unloading, average time for picking/retrieving of the items, etc.). This will led to apply it to more complex scenarios, thus ensuring greater flexibility and increasing the number of the industrial environment to be applied. 


\section{Acknowledgements}

The paper has been written within the framework of the project PON04a2_E "Smart Energy Master per il governo energetico del territorio - SINERGREEN - RES NOVAE". This project is supported by the Italian University and Research National Ministry research and competitiveness program that Italy is developing to promote "Smart Cities Communities and Social Innovation".

\section{References}

[1] S. Digiesi, G. Mossa, G. Mummolo, A loss factor based approach for sustainable logistics, Production Planning \& Control, 23 (2012), 160-170.

[2] S. Digiesi, G. Mossa, G. Mummolo, A sustainable order quantity model under uncertain product demand, in: 7th IFAC Conference on Manufacturing Modelling, Management, and Control, Saint Petersburg, 2013, pp. 664-669.

[3] A. McKinnon, S. Cullinane, A. Whiteing, M. Browne, Green logistic: improving the environmental sustainability of logistics, first ed., Kogan Page Publishers, London, 2010.

[4] R. De Koster, T. Le-Duc, K. J. Roodbergen, Design and control of warehouse order picking: A literature review, European Journal of Operational Research, 182 (2007), 481-501.

[5] J. A. Tompkins, J. A. White, Y. A. Bozer, E. H. Frazelle, J. M. A. Tanchoco, Facilities planning, John Wiley, New York, 2003.

[6] C. G. Petersen, G. Aase, A comparison of picking, storage, and routing policies in manual order picking, International Journal of Production Economics, 92 (2004), 11-19.

[7] V. R. Muppani, G. K. Adil, A branch and bound algorithm for class based storage location assignment, European Journal of Operational Research, 189 (2008), 492-507.

[8] F. T. S. Chan, H. K. Chan, Improving the productivity of order picking of a manual-pick and multi-level rack distribution warehouse through the implementation of class-based storage, Expert Systems with Applications, 38 (2011), 2686-2700.

[9] G. Dukic, C. Oluic, Order-picking Routing Policies: Simple Heuristics, Advanced Heuristics and Optimal Algorithm, Journal of Mechanical Engineering 50 (2004), 530-535.

[10] H. Hwang, Y. H. Oh, Y. K. Lee, An evaluation of routing policies for order- picking operations in low-level pickerto-part system, International Journal of Production Research, 42 (2004), 3873-3889.

[11] J. Gu, M. Goetschalckx, L. F. McGinnis, Research on warehouse design and performance evaluation: A comprehensive review, European Journal of Operational Research, 203 (2010), 539-549.

[12] J.V. Spadaro, A. Rabl, Estimates of real damage from air pollution: Site dependence and simple impact indices for LCA. International, Journal Life Cycle Assesment, 4 (1999), 229-243.

[13] M.G. Gnoni, R. Iavagnilio, G. Mossa, G. Mummolo, Modelling dynamics of a supply chain under uncertainty: A case from the automotive industry, International Journal of Automotive Technology and Management, 3 (2003), 354-367.

[14] A. Fumi, L. Scarabotti, M.M. Schiraldi, The effect of Slot-Code Optimization in Warehouse Order Picking, International Journal of Engineering Business Management, 5 (2013), 1-10. 